\title{
The Causal Linkages of Human Development Index and Economic Complexity Index: a Panel Analysis for Selected OECD Countries
}

\author{
Feyza Arica $^{1 *}$, Unzule Kurt ${ }^{2}$ \\ ${ }^{1}$ Çanakkale Onsekiz Mart University / Biga Faculty of Economics and Administrative Sciences, \\ Economics \\ e-mail: feyzarica@gmail.com \\ ${ }^{2}$ Çanakkale Onsekiz Mart University/Biga Faculty of Applied Sciences, Finance and Banking \\ e-mail: unzulekurt17@gmail.com
}

DOI: 10.51865/EITC.2021.03.03

\begin{abstract}
Economic theory debates that sustainable economic growth occurs through economic development. Successful development strategies substantially depend on a fast pace of growth and measured pace of economic openness. In this context, the Economic Complexity Index (ECI), which is the compound of a country's productive output have provided important insights into patterns of economic development.

This study investigates the impact of the Human Development Index (HDI) on ECI in selected 24 OECD countries. Using panel data methodology for the period 1995-2018, the results of the study show that there has been a unidirectional causality running from economic complexity to human development in five developed countries, but human development Granger cause economic complexity in six countries. In addition, the feedback effect exists between human development and economic complexity for Spain at the $5 \%$ level of significance, indicating that both economic complexity and human development are influencing each other. Thus, the study emphasizes that for increasing the knowledge intensity of selected country groups there is a need to increase their accumulation of human capital in selected OECD countries.
\end{abstract}

Keywords: human development; product diversification; economic complexity.

JEL Classification: C23; O14; $O 15$.

\section{Introduction}

Many research findings focusing on successful development strategies showed that the manufacturing sector has been played an important role in stimulating economic growth processes. In order to this, especially many countries try to obtain biggest share of the pie by increasing their competitiveness in global trade. This can be realized by more integrated technology boost production volumes.

\footnotetext{
* Corresponding author
} 
From this point of view, the recent Atlas of Economic Complexity developed by Hausmann and Hildalgo et al. (2011) occur as important empirical innovation, which states production sophistication as an important source to provide development. On the other hand, the HDI represents the enhancement of human capital which has been recognized as one of the major factors of the real wealth of nations.

This study aims to examine the empirical relationship between the economic complexity and human development indexes. This study is organized into four sections. Section two indicates the linkage between human development and economic complexity and outlines the related literature, section three discusses the data and the methodology and presents the empirical evidences and lastly section four finals the study.

\section{The Linkage of Human Development, Economic Complexity and Growth}

The search for and construction of appropriate predictors of economic development are among the fundamental goals of economists and policymakers. Education, infrastructure, rule of law, and quality of governance are all among the commonly used indicators based on inputs. Especially, technological complexity plays an important role in boosting the development of new skills and human capital formation, and is thus critical for the growth rate of the economy (Ferrarini and Scaramozzino, 2013).

The recently Economic Complexity Index emerged as a new predictor of economic development characterizing diversity of the economy as a system (Gnutzmann-Mkrtchyan, 2016).

In measuring a country's "economic complexity", Hausmann and Hildalgo et al. (2011) analyzed a given country's exports basket over 50 years starting in 1963. In the methodology, whether a country is economically complexity hinges on the two basic concepts, the ubiquity and diversity of the products in its exports basket. More clearly, if a particular economy is capable of producing rare and complex goods, this implies the existence of a sophisticated productive structure. Additionally, goods that are non-ubiquitous are goods that have high technological content and are therefore difficult to produce and goods that are very scarce by nature (Gala et al. 2018: 226).

Human development refers to the process of enlarging the freedom, opportunities, and wellbeing of the people residing in a country. Human development represents the enhancement of human capital which has been recognized as one of the major factors of the real wealth of nations. It defines the development in the capacities knowledge, skills, abilities and health of individuals which can improve their economic performances. The development of these capacities plays an important part in the economic growth of a country (Rahman et al. 2020).

The empirical papers, examining the relationship of economic complexity-human development have been rarely seen in related literature. For example, using the data provided by the Atlas of Economic Complexity, Gala et al. (2018) showed that the higher the complexity of developing countries export basket, the higher the probability of income convergence with high-income countries.

Ramirez et al (1998) investigated the relationship of economic growth-human development using cross-country statistics over the period 1970-92. They showed that there has been a strong positive relationship in both directions of the relationship between the two variables.

Felipe et al. (2012) examined the relationship between economic development and product complexity. They connect economic development with the production of higher complexity products. They find that the more complex products are exported mainly by the richer countries 
while the less complex products are exported by the poorer countries. Additionally, they estimate cross-country regressions of each country's export share for 5107 products. The results show that exports increase with income for high complexity products, whereas for low complexity products exports decrease with income (Kapartzanis, 2018).

Lapatinas (2016) investigated empirically the impact of economic complexity on human development. Examining the existence of a causal effect between economic diversification and social development, Lapatinas (2016) used pooled OLS with fixed effects. So, he finds a positive relationship between economic diversification and human development.

Examining the relationship between economic complexity and growth for Southeastern and Central European Countries, Stojkoski and Kocarev (2017) found a significant and positive relationship in long run relationship for the years 1995 and 2013 by using panel dynamic OLS.

Using OLS and Fixed Effects, Zhu and Li (2017) investigated the linkages among human capital, economic complexity and growth for 126 countries over the period 1995-2010. They found that both complexity and human capital have significantly positive impact on economic growth.

Rahman et al. (2020) investigated the effect of human development on economic growth for 25 developed and 25 developing countries during the period 2000-2014. The results obtained from OLS, fixed effects and random effects showed that there has been a significantly positive connection between the two variables in the cases of both country group.

Mewes and Broekel (2020) examined the relationship between the complexity of technological activities and economic growth in 159 European NUTS 2 regions for the years 2000-2014. Their empirical findings suggest that technological complexity is an important predictor of regional economic growth.

\section{Data and Econometric Methodology}

\section{Data}

This paper institutes an econometric model to illustrate the relationship between economic complexity and human development. In the analyzing of this relationship between the variables by incorporating a balanced panel, the followed the linear panel data specification is shown below:

$$
E C I_{i t}=c+\beta_{1} H D I_{i t}+u_{i t}
$$

where ECI is economic complexity index, which is an index created by Atlas Media on countries' production of products with high value added. HDI is Human development index that give the information about life expectancy, education (literacy rate, gross enrollment ratio at different levels and net attendance ratio), and per capita income of a country. The annual and available data has been collected from Human Development Report (UNDP).

Figure 1 shows the development of economic complexity for selected 24 OECD countries between 1995 and 2018. According to Figure 1, we see that the economic complexity has diverged over time, although there is some similarity in the rankings among countries over time. 
$\mathrm{ECl}$

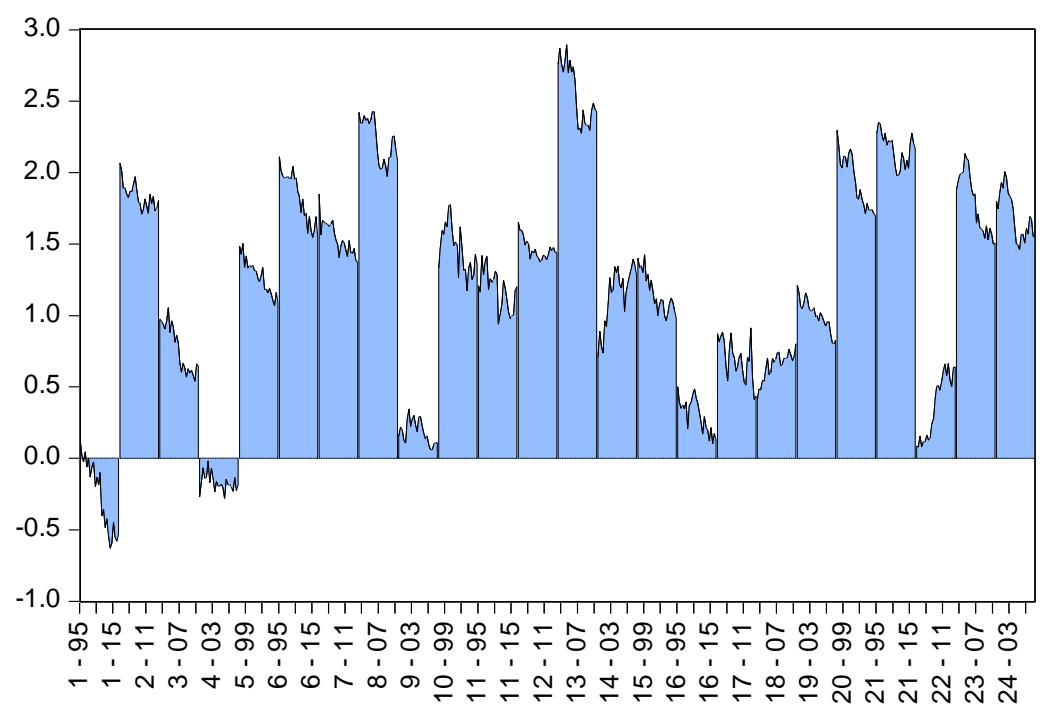

Fig. 1. Economic complexity

Source: Authors' calculations using The Atlas of Economic Complexity Data Center.

Figure 2 shows the development of human development index for selected 24 OECD countries between 1995 and 2018. According to Figure 1, we see that there is an increasing trend over the years in the countries' hdi value.

HDI

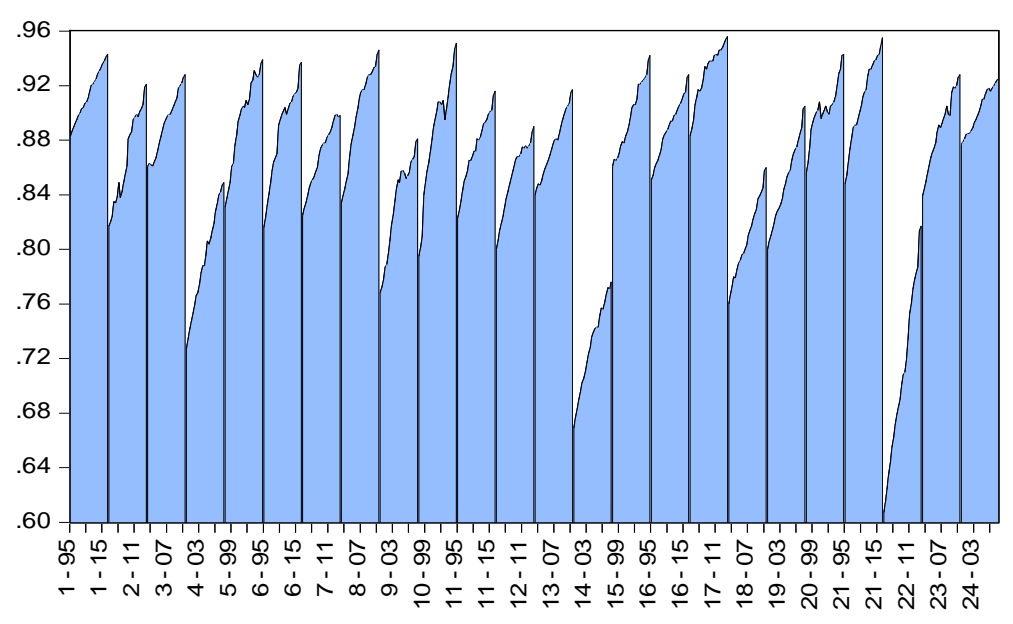

Fig. 2. Human Development Index

Source: Authors' calculations using UNDP Human Development Reports 2020.

Table 1 shows that the mean value of Economic Complexity Index (ECI) is 1.19. The maximum value has been observed at the 2.89 and the minimum level remained at -0.62 . The standard deviation is calculated at the level 0.76 which is the sign that there are fewer deviations from the average value of ECI. If we look at the values of Human Development Index (HDI), the maximum value has been observed at the 0.95 and the minimum level remained at 0.60 . The standard deviation is calculated at the level 0.06 which is the sign that there are fewer deviations from the average value of HDI. 
Table 1. Descriptive Statistics of the Variables Regarding ECI and HDI

\begin{tabular}{|l|c|c|}
\hline Descriptive Statistics & ECI & HDI \\
\hline Mean & 1.199241 & 0.865019 \\
\hline Median & 1.288300 & 0.880500 \\
\hline Maximum & 2.895100 & 0.956000 \\
\hline Minimum & -0.628400 & 0.607000 \\
\hline Std. Dev. & 0.761015 & 0.062153 \\
\hline Skewness & -0.247646 & -1.422988 \\
\hline Kurtosis & 2.344676 & 5.218085 \\
\hline Jarque-Bera & 16.19432 & 312.4676 \\
\hline Probability & 0.000304 & 0.000000 \\
\hline Sum & 690.7628 & 498.2510 \\
\hline Sum Sq. Dev. & 333.0078 & 2.221197 \\
\hline Observations & 576 & 576 \\
\hline
\end{tabular}

Source: Authors' own and all the calculations are carried out by E-views 9.0.

\section{Econometric methodology and empirical findings}

\section{Unit root analysis}

It must be controlled if there is unit root in the series to get unbiased estimations. In this study, Hadri and Kurozumi (2012)'s (H-K) panel stationarity test is used. H-K (2012) test states that under a null hypothesis, series do not contain unit root, while an alternative hypothesis states that series contain unit root. In addition, this test allowing serial correlation and cross-sectional dependence can be used in which both $\mathrm{T}<\mathrm{N}$ and $\mathrm{T}>\mathrm{N}$.

H-K (2012) used the following equation:

$$
y_{i t}=k_{t}^{\prime} \delta_{i}+f_{t} \cdot \gamma_{i}+\varepsilon_{i t}, \varepsilon_{i t}=\phi_{i 1} \cdot \varepsilon_{i t-1}+\ldots+\phi_{i p} \cdot \varepsilon_{i t-p}+v_{i t}
$$

for $\mathrm{i}=1, \ldots, \mathrm{N}, \mathrm{t}=1, \ldots, \mathrm{T}$, where ${ }^{z_{t}^{\prime}}$ is deterministic, ${ }^{\prime} \delta_{i}$ represents the individual effects, $f_{t}$ is an unobserved common factor, $\gamma_{i}$ is the loading factor, and ${ }^{\varepsilon_{i t}}$ denotes the individual-specific error. H-K (2012) regress $y_{i t}$ on $w_{t}=\left[k^{\prime}{ }_{t}, \bar{y}_{t}, \bar{y}_{t-1}, \ldots, \bar{y}_{t-p}\right]$ to correct the cross-sectional dependence, for each $\mathrm{i}$, construct the following the statistic:

$$
Z_{A}=\frac{\sqrt{N} \overline{(S T}-\xi)}{\zeta}
$$

where $\overline{S T}=1 / N \cdot \sum_{i=1}^{N} S T_{i}$ with $S T_{i}=\frac{1}{\hat{\sigma}_{i}^{2} \cdot T^{2}} \sum_{t=1}^{T} S^{w}{ }_{i t}$, where $S_{i t}{ }^{w}=\sum_{r=1}^{t} \hat{\varepsilon}_{i r}, \hat{\sigma}_{i}^{2}$ is the estimator of the long-run variance.

H-K (2012) calculate estimator of the long-run variance by:

$$
\hat{\sigma}_{i S P C}^{2}=\frac{\hat{\sigma}_{v i}^{2}}{\left(1-\hat{\varphi}_{i}\right)^{2}}
$$

where $\hat{\sigma}_{v i}^{2}=1 / T \cdot \sum_{t=1}^{T} \hat{v}_{i t}^{2} \quad \hat{\varphi}_{i}=\min \left\{1-\frac{1}{\sqrt{T}}, \sum_{j=1}^{p} \hat{\varphi}_{i j}\right\}$.

and H-K (2012) institutes $Z_{A}^{S P C}$ as below: 


$$
Z_{A}{ }^{S P C}=\frac{1}{\hat{\sigma}_{i S P C}^{2} \cdot T^{2}} \sum_{t=1}^{T}\left(S_{i t}{ }^{w}\right)^{2}
$$

The $Z_{A}^{S P C}$ is preferred over the $Z_{A}$ in case of cross-sectional dependence.

Table 2 shows the panel stationarity test results. According to Table 1, the null hypothesis of a stationarity cannot be rejected at the 5\% significance level for all variables.

Table 2. Results for the H-K (2012) stationary test

\begin{tabular}{|c|c|c|}
\hline \multicolumn{1}{|c|}{ Series } & ZA-Spac Test Statistic & p-value \\
\hline ECI & -3.013 & 0.99 \\
\hline HDI & -3.470 & 0.99 \\
\hline
\end{tabular}

Source: Authors' calculations.

\section{Causality Analysis}

The causal relationship between the variables is analyzed by Emirmahmutoglu and Köse (2011) (E-K) and Dumitrescu and Hurlin (2012) (D-H) causality tests.

\section{The Dumitrescu-Hurlin causality test}

Under the null hypothesis, D-H (2012) assumes that there is no individual causality relationship from $\mathrm{x}$ to $\mathrm{y}$ exists. This hypothesis is denoted the Homogeneous Non Causality (HNC) hypothesis. Under the alternative hypothesis, it is assumed that there is a causal relationship from $\mathrm{x}$ to $\mathrm{y}$ for a subgroup of individuals and $\beta_{i}$ may differ across groups.

The D-H (2012) test results are shown in Table 3. According to the findings, Human development does Granger cause economic complexity index. Thus, the results revealed a oneway causality runs from human development index to economic complexity.

Table 3. Results for the D-H (2012) Panel Granger Non-Causality Test

\begin{tabular}{|c|c|c|c|}
\hline \multicolumn{4}{|l|}{ Lags: 2} \\
\hline Null Hypothesis: & W-Stat. & Zbar-Stat. & Prob. \\
\hline $\mathrm{ECI} \longrightarrow-\mathrm{HDI}$ & 2.48942 & 0.42100 & 0.6738 \\
\hline $\mathrm{HDI} \stackrel{\mathrm{ECI}}{\rightarrow}$ & $5.90108 * * *$ & 6.86910 & 6.E-12 \\
\hline
\end{tabular}

$* * * 1 \%$ significance level.

Source: Authors' calculations.

\section{The Emirmahmutoglu-Kose (E-K) causality test}

To examine whether economic complexity causes human development or human development causes economic complexity, we apply the Emirmahmutoglu and Kose (2011) panel causality test as an other test. E-K (2011) developed a causality procedure that is based on the TodaYamamoto causality procedure. The E-K test is modified by the lag augmented VAR approach. We employ the lag augmented VAR model with $\mathrm{k}_{\mathrm{i}}+\mathrm{dmax}_{\mathrm{i}}$, lags in heterogenous mixed panels:

$$
\begin{gathered}
E C I_{i t}=\alpha_{i}^{E C I}+\sum_{j=1}^{k_{i}+d \max _{i}} A_{11, i j} E C I_{i, t-j}+\sum_{j=1}^{k_{i}+d \max _{i}} A_{12, i j} H D I_{i, t-j}+u^{E C I}{ }_{i t} \\
H D I_{i t}=\alpha_{i}^{H D I}+\sum_{j=1}^{k_{i}+d \max _{i}} A_{21, i j} E C I_{i, t-j}+\sum_{j=1}^{k_{i}+d \max _{i}} A_{22, i j} H D I_{i, t-j}+u_{i t}^{H D I}
\end{gathered}
$$

where $\mathrm{k}_{\mathrm{i}}$ is the lag orders in VAR systems for ith country selected by Akaike information criteria, $\alpha_{\mathrm{i}}$ of HDI and ECI are the fixed effect vectors. E-K use Fisher test statistic in order to test the Granger non-causality hypothesis in panel system. Fisher test statistic ( $\lambda)$ is as follows: 


$$
\eta=-2 \cdot \sum_{i=1}^{N} \ln \left(p_{i}\right) \mathrm{i}=1,2, \ldots, \mathrm{N}
$$

where $p_{i}$ shows the $p$-value of the Wald statistics of the ith individual cross-section.The E-K causality test can be applied if the variables are stationary at $\mathrm{I}(1)$ or $\mathrm{I}(0)$. That is, there is no need to test for the presence or absence of cointegration between the variables. Lastly, the simulation results of the test under both the cross-section independency and the cross-section dependency showed that it performs well even if $\mathrm{N}$ and $\mathrm{T}$ are small (Emirmahmutoglu and Kose, 2011).

The results of Granger causality test proposed by E-K (2011) are reported in Table 4. We find unidirectional causality running from economic complexity to human development in five developed countries: Denmark (at 5\%), Greece (at 10\%), New Zealand (at 1\%), Spain (at 1\%) and Turkey (at 10\%), but human development Granger cause economic complexity in six countries: Austria (at 1\%), France (at 10\%), Japan (at 10\%), Netherlands (at 5\%), Spain (at $10 \%$ ) and USA (at 5\%). The feedback effect exists between economic complexity and human development for Spain at the 5\% level of significance, indicating that both economic complexity and human development are influencing each other.

Table 4. Results of E-K (2011) test

\begin{tabular}{|l|c|c|c|c|c|}
\hline Country-specific results & \multicolumn{5}{l|}{} \\
\hline Country & Lag & ECI=>HDI & p-value & HDI=>ECI & p-value \\
\hline Australia & 1.000 & 2.179 & 0.140 & 0.643 & 0.423 \\
\hline Austria & 3.000 & 3.733 & 0.292 & $13.814^{* * *}$ & 0.003 \\
\hline Canada & 1.000 & 0.003 & 0.957 & 0.328 & 0.567 \\
\hline Chile & 1.000 & 0.023 & 0.880 & 1.171 & 0.279 \\
\hline Denmark & 1.000 & $6.527^{* *}$ & 0.011 & 0.242 & 0.623 \\
\hline Finland & 2.000 & 4.552 & 0.103 & 1.117 & 0.572 \\
\hline France & 2.000 & 1.090 & 0.580 & $5.798^{*}$ & 0.055 \\
\hline Germany & 1.000 & 1.086 & 0.297 & 0.864 & 0.353 \\
\hline Greece & 3.000 & $7.209^{*}$ & 0.066 & 3.660 & 0.301 \\
\hline Ireland & 1.000 & 0.078 & 0.780 & 1.213 & 0.271 \\
\hline Israel & 1.000 & 0.117 & 0.732 & 1.055 & 0.304 \\
\hline Italy & 1.000 & 0.716 & 0.397 & 2.285 & 0.131 \\
\hline Japan & 1.000 & 2.115 & 0.146 & $3.490^{*}$ & 0.062 \\
\hline Mexico & 1.000 & 0.216 & 0.642 & 2.408 & 0.121 \\
\hline Netherlands & 3.000 & 1.241 & 0.743 & $8.628^{* *}$ & 0.035 \\
\hline New Zealand & 1.000 & $7.815^{* * *}$ & 0.005 & 0.013 & 0.909 \\
\hline Norway & 3.000 & 2.726 & 0.436 & 1.070 & 0.784 \\
\hline Portugal & 3.000 & 1.901 & 0.593 & 5.221 & 0.156 \\
\hline Spain & 3.000 & $14.122^{* * *}$ & 0.003 & $7.045^{*}$ & 0.070 \\
\hline Sweden & 1.000 & 0.044 & 0.835 & 1.153 & 0.283 \\
\hline Switzerland & 1.000 & 0.097 & 0.756 & 0.012 & 0.912 \\
\hline Turkey & 3.000 & $7.409^{*}$ & 0.060 & 5.420 & 0.144 \\
\hline UK & 1.000 & 0.731 & 0.392 & 0.009 & 0.926 \\
\hline USA & 1.000 & 0.511 & 0.475 & $3.932^{* *}$ & 0.047 \\
\hline
\end{tabular}

$* * * 1 \%, * * 5 \%$ and $* 10 \%$ significance levels.

Source: Authors' calculation.

\section{Concluding Remarks}

Economic complexity gradually gained more importance for country economies. Looking at the developed and fast growing countries today, it is seen that they invest a lot in R\&D to obtain more complex products. Because, obtaining more complex goods instead of raw materials and 
basic goods causes the country to increase its competitiveness and its earnings (Erkan and Yildirimci, 2015).

This study aims to reveal the linkages between economic complexity and human development 24 OECD countries using annual dataset from the period 1995 to 2018. The results of the study show that there has been a unidirectional causality running from economic complexity to human development in five developed countries, but human development Granger cause economic complexity in six countries.

In addition, the feedback effect exists between economic complexity and human development for Spain at the 5\% level of significance, indicating that both economic complexity and human development are influencing each other. Empirical evidence from a cross-section of countries is consistent with the theoretical predictions and supports the view that human development is important to explain differences in economic complexity as a proxy variable of economic performance.

\section{References}

1. Dumitrescu, E.-I. and Hurlin, C. (2012). Testing for Granger non-causality in heterogeneous panels. Economic Modelling, 29(4), 1450-1460.

2. Emirmahmutoglu, F. and Kose, N. (2011). Testing for granger causality in heterogeneous mixed panels. Economic Modeling, 28, 870-876.

3. Erkan, B. and Yildirimci, E. (2015). Economic Complexity and Export Competitiveness: The Case of Turkey. Procedia - Social and Behavioral Sciences, 195: 524 - 533.

4. Felipe, J., Kumar, U., Abdon, A. and Bacate, M. (2012). Product complexity and economic development. Structural Change and Economic Dynamics, 23(1): 36-68.

5. Ferrarini, B. and Scaramozzino, P. (2013). Complexity, Specialization, and Growth, ADB Economics Working Paper Series, No. 344.

6. Gala, P., Rocha, I. and Magacho,G. (2018). The Structuralist Revenge: Economic Complexity as an Important Dimension to Evaluate Growth and Development", Brazilian Journal of Political Economy, 38: 219-236.

7. Gnutzmann-Mkrtchyan, A. (2016). The Economic Complexity of Transition Economies, Free Policy Network Brief Series. Available through https://freepolicybriefs.org/wpcontent/uploads/2016/03/FREEPolicyBriefs_Mar29.pdf.

8. Hadri, K. and Kurozumi, E., (2012). A Simple Panel Stationarity Test in the Presence of Serial Correlation and a Common Factor, Economics Letters, 115, 31-34.

9. Hausmann, R. and Hidalgo, C. A. (2011). The network structure of economic output. Journal of Economic Growth 16(4), 309-342.

10. Hidalgo, C. A. and Hausmann, R. (2009). The building blocks of economic complexity. Proceedings of the National Academy of Sciences 106(26), 10570-10575.

11. Inoua, S. (2016). A Simple Measure of Economic Complexity. arXiv preprint arXiv:1601.05012.

12. Kapartzanis, P. (2018). Unlinking Causally Economic Complexity and Income Inequality, University of Ioannina Department of Economics MSc Economic Analysis.

13. Lapatinas, A. (2016). Economic complexity and human development: a note. Economics Bulletin, 36(3), 1441-1452.

14. Mewes, L. and Broeker, T. (2020). Technological complexity and economic growth of regions, Research Policy.

15. Raja, A. R., Muhammad, A. R. and Conor, R. (2020). The Impact of Human Development on Economic Growth: A Panel Data Approach (January 28, 2020). Available through SSRN: https://ssrn.com/abstract=3526909 or http://dx.doi.org/10.2139/ssrn.3526909.

16. Ramirez, A, Ranis, G. and Stewart, F. (1998). Economic Growth and Human Development. QEH Working Paper Series - QEHWPS18 Number 18.

17. Stojkoski, V. and Kocarev, L. (2017). The Relationship Between Growth and Economic Complexity: Evidence from Southeastern and Central Europe. MPRA Paper No. 7783, Munich Personal RePEc Archive.

18. Zhu, S. and Li, R. (2017). Economic complexity, human capital and economic growth: empirical research based on cross-country panel data. Applied Economics, 49(38): 3815-3828. 